\title{
Use of a special inhaler attachment in asthmatic children
}

\author{
R ELLUL-MICALlEF, F MORÉN, K WETTERLIN, AND K C HIDINGER \\ From the Department of Medicine, University of Kuwait, and AB Draco, \\ Research and Development Laboratories, Lund, Sweden
}

ABSTRACT Asthmatics often find difficulties in using an aerosol inhaler correctly as they are unableo to co-ordinate the release of a bolus of drug to coincide with an inspiratory effort. This is especiallig the case with children. The addition of a special attachment to an ordinary inhaler overcame this problem. Twelve asthmatic children produced significantly better PEFR measurements when $0 \cdot 25 \mathrm{mg}$. terbutaline sulphate was administered via an inhaler with the attachment than when an ordinar inhaler was used alone.

A problem not infrequently faced by doctors when treating asthmatic patients is the inability of some patients to use a pressurised aerosol correctly. ${ }^{1-3}$ Difficulties of ten arise with patients being unable to co-ordinate the release of a bolus of drug from the aerosol with inspiration. Such a problem is present to an even greater extent in children.

There is evidence which shows that only between $10-25 \%$ of the dose of drug administered from a pressurised aerosol actually gets into the lungs. ${ }^{4-5}$ The greater part of the drug is swallowed after deposition in the mouth and as a result of mucociliary clearance, and may be absorbed from the gastrointestinal tract. ${ }^{6-8}$ The availability of an inhaled drug to the airways depends largely on droplet size, provided the aerosol inhaler is properly used. It is known that droplet size from a pressurised aerosol is dependent on the formulation and the time fo $\overrightarrow{50}$ evaporation of the propellant. ${ }^{9}$ In a previous study it was shown that the deposition of drug in the mouth could be significantly reduced as the distance from the inhaler orifice to th $\overrightarrow{5}$ mouth was increased simply by attaching a tubs to the inhaler. ${ }^{10}$ The present study was designe $\Phi$ to find out whether the attachment of a speciat tube called a "spacer" when attached to an in 3 haler would facilitate its use by asthmatie children and whether the presumed increase in. availability of the drug would result in better pulmonary function.

\section{Patients and methods}

Twelve children all suffering from extrinsi8 bronchial asthma agreed to participate in the study (table). Informed consent was obtaineg

Table Summary of data on study patients

\begin{tabular}{|c|c|c|c|c|c|c|}
\hline Patient & Age (yr) & Sex & $\begin{array}{l}\text { Duration } \\
\text { of asthma (yr) }\end{array}$ & $\begin{array}{l}F E V_{1} \\
\text { Predicted }(\mathrm{ml})\end{array}$ & $\begin{array}{l}F E V_{1} \\
\text { Initial }(m l)\end{array}$ & $\begin{array}{l}F E V_{1} \\
\text { Post-inhalation }(\mathrm{ml})\end{array}$ \\
\hline 1 & 11 & $\mathbf{M}$ & 7 & 1400 & 975 & 1225 \\
\hline 2 & 11 & $\mathbf{M}$ & 9 & 1650 & 1150 & 1450 \\
\hline 3 & 7 & $\mathbf{M}$ & 6 & 1250 & 875 & 1100 \\
\hline 4 & 10 & $\mathbf{F}$ & 7 & 1400 & 950 & 1150 \\
\hline 5 & 10 & $\mathbf{F}$ & 6 & 1800 & 1200 & 1500 \\
\hline 6 & 7 & $\mathbf{F}$ & 5 & 1350 & 800 & 950 \\
\hline 7 & 8 & $\mathbf{M}$ & 4 & 1250 & 850 & 1100 \\
\hline 8 & 7 & $\mathbf{M}$ & 1 & 1300 & 900 & 1150 \\
\hline 9 & 9 & $\mathbf{M}$ & 6 & 1600 & 1150 & 1350 \\
\hline 10 & 7 & $\mathbf{F}$ & 2 & 1300 & 850 & 1000 \\
\hline 11 & 9 & $\mathbf{M}$ & 5 & 1600 & 1050 & 1200 \\
\hline 12 & 7 & $\mathbf{M}$ & 6 & 1400 & 1050 & 1250 \\
\hline
\end{tabular}


from their parents. All children attended an outpatient clinic on four separate occasions at approximately weekly intervals. On the first visit their reversibility to a bronchodilator was determined by measuring their forced expiratory volume in one second $\left(\mathrm{FEV}_{1}\right)$. On the subsequent visit skin testing was carefully carried out by means of the prick technique using Bencard's solutions, blood was taken for a haemoglobin estimation and absolute eosinophil count, and where possible sputum was sent for bacteriological examination. During both these visits the children familiarised themselves with a peak flow meter. On the next two visits the children were randomly allocated in a cross-over manner to inhale $0.25 \mathrm{mg}$ of terbutaline sulphate (Bricanyl R) delivered in one puff from an ordinary inhaler or from one attached to the special "spacer" provided. The spacer consisted of a collapsible tube which could be easily and tightly attached to the inhaler. Figures 1 and 2 show the tube in diagrammatic form when collapsed and when ready for use. Its volume is about $750 \mathrm{ml}$. Valves have been included in the

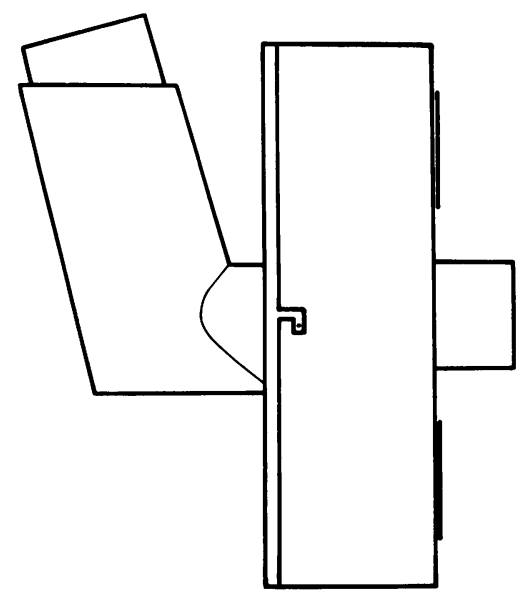

Fig 1 Drawing of inhaler attached to collapsed spacer. design of the spacer in such a way as to allow the subject to breathe comfortably through the spacer mouthpiece. The peak expiratory flow (PEFR) was measured in all instances by the author using a Wright peak flow meter for children; the instrument was calibrated regularly against a rotameter. ${ }^{11}$ Measurements were recorded immediately before, 5,20 , and 60 minutes later. The best of three successive efforts was recorded each time. Statistical significance has been tested for by means of Student's $t$ test. ${ }^{12}$ When readings of peak flow around the maximum of the children's meter were obtained, an adult meter, similarly calibrated, was used.

\section{Results}

There was excellent co-operation from all the children, most of whom were very interested in the sfacer. There was good reversibility of their airway obstruction after a bronchodilator as shown by their $\mathrm{FEV}_{1}$ values in the table. All children had markedly positive skin reactions to at least three of the allergens with which they were tested. Haemoglobin values were all normal and bacteriological examination of the sputum failed to reveal any pathogens when it was carried out. Chest radiographs were all normal except in patient 3 where a minor deformity of the rib cage was present.

All 12 children showed a statistically signifir cant improvement in the PEFR values compared. to pre-treatment measurements on the three occasions when measured, both when the inhaler was used alone and when it had the spacer attached to it $(p<0.001)$. Figure 3 shows the effect of inhaled terbutaline when this was administered by the two different methods. The mean peak effect occurred 20 minutes after drug administration in both cases. When the inhaler was used on its own, the peak value for PEFR was $181 \pm 61 / \mathrm{mm}^{-1}$ (mean \pm SEM); after attachment of the spacer the corresponding values were $206 \pm 61 / \mathrm{mm}^{-1}$ (mean \pm

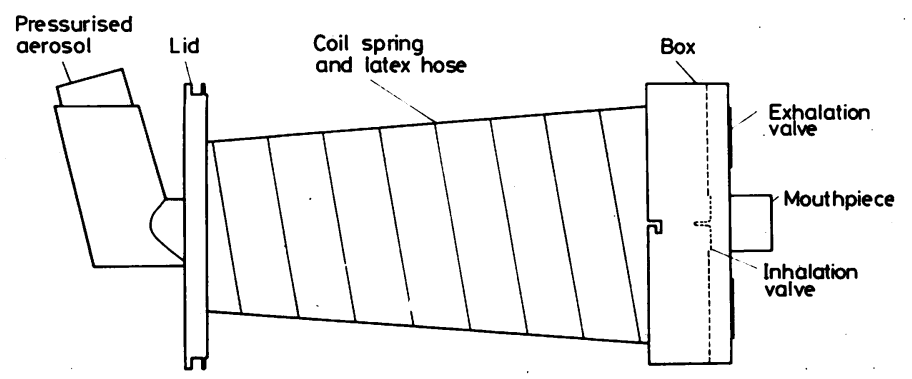

Fig 2 Drawing of inhaler attachment to spacer when ready for use. 


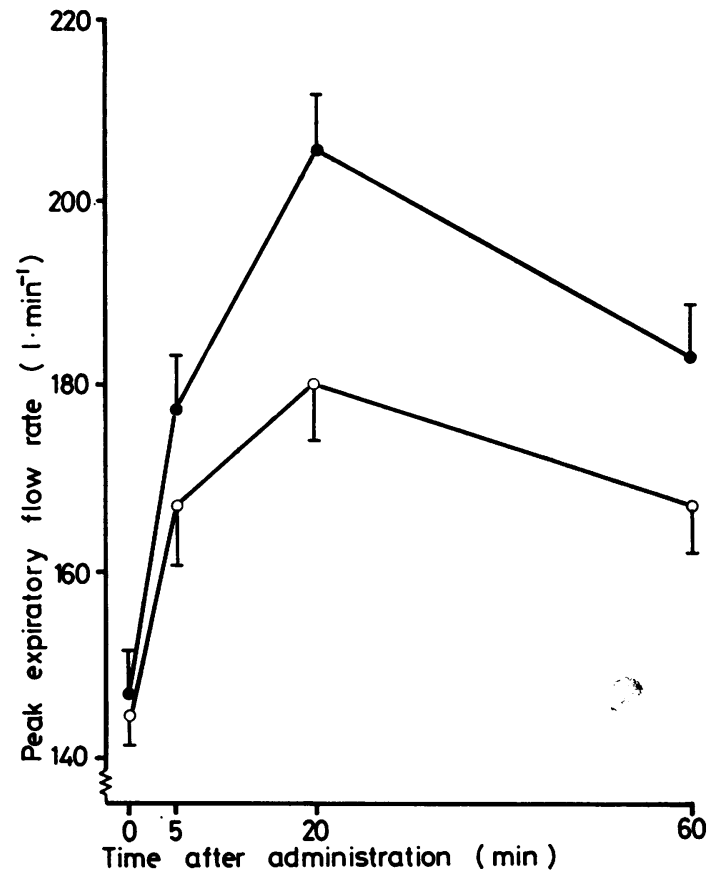

Fig 3 Mean increase in PEFR and standard error of mean at intervals after administration of $0.25 \mathrm{mg}$ terbutaline sulphate by inhalation. $\mathrm{O}=$ actuator. $\mathrm{O}=$ actuator provided with collapsible tube.

SEM). The values obtained when the spacer was attached were significantly greater when measured 20 and 60 minutes after therapy $(\mathrm{p}<0.001, \mathrm{p}<0.01)$.

\section{Discussion}

The increased distance from the inhaler to the mouth allowed deceleration of the aerosol particles and increased the time available for evaporation of the propellant. Lower velocity and smaller particle size are known to result in diminished impaction. ${ }^{13}$ Previous work has shown that least drug impaction in the device and mouth occurred when the particles from a pressurised aerosol are collected in a large defined volume. Collecting the particles in such a volume before inhalation means that the drug aerosol can be inhaled with a greater part of the inspiratory volume. Valves were adapted to the spacer to control the airflow for inhalation and exhalation allowing the aerosol particles to be carried only by the inspiratory flow from the spacer. ${ }^{14}$ The need to co-ordinate the release of the drug from the inhaler to inspiration is eliminated. This is of obvious advantage to? children as well as to adults who have difficultie? in using an inhaler properly. The great majority of children were unable to use the inhaler in proper way. The investigator had to actuate the inhaler for them in the inspiratory phase. NE such problems arose when the spacer was attached to the inhaler.

Pulmonary function changes after the drus therapy in bronchial asthma seem to be related to the initial degree of airway obstruction 1 and on whether this degree of obstruction was్ reached via a path of improvement or deterioraio tion. ${ }^{16}$ Although there were differences in the initial values of PEFR when the drug was deO livered from an ordinary inhaler and when a spacer was attached, these were small and not statistically significant. $(0 \cdot 5>p>0 \cdot 1)$. On bot occasions all 12 children suffered from a modere ate degree of asthma. Adding the spacer to the inhaler allowed the children to use the inhale $\overrightarrow{0}$ without any help and resulted in significantly better pulmonary function.

We are grateful to $\mathrm{Mr} \mathrm{E}$ Braun and $\mathrm{Mr} \mathrm{YE}$ Lindahl at the Central Workshop, Chemicad Centre, University of Lund, Sweden, for con尺 structional work.

\section{References}

1 Paterson IC, Crompton GK. Use of pressurize aerosols by asthmatic patients. Br Med J 1976 1:76-7.

2 Arvastson B, Björkander J, Eklundh G et a Hur tar patienten sin bronkdilaterande doso aerosol? Lärkertidningen 1976; 73:1407-9.

3 Orehek J, Gayrard P, Grimaud C, Charpin Patient error in use of bronchodilator metered aerosols. $\mathrm{Br}$ Med J 1976; 1:76.

4 Martin LE, Harrison C, Tanner RJN. Metab음 olism of beclomethasone dipropionate bP animals and man. Postgrad Med J 1975; 51월 11-20.

5 Davies DS. Pharmacokinetics of inhaled sub stances. Scand J Resp Dis 1979; suppl no 103 44-9.

6 Hatch TF, Gross P. Pulmonary deposition an retention of inhaled aerosols. New York. Academic Press, 1964: 35.

7 Blackwell EW, Conolly ME, Davies DS, Doller CT. The fate of isoprenaline administered by pressurized aerosols. Br J Pharmacol 1970; 39.0 194-5P.

8 Nilsson HT, Simonsson BG, Ström B. The fate of ${ }^{3} \mathrm{H}$-terbutaline sulphate administered to maro as an aerosol. Eur J Clin Pharmacol 1976; 10: 1-7.

9 Weiner MV. How to formulate aerosols 
obtain the desired spray pattern. J Soc Cosmet Chem 1958; 9:289-97.

10 Morén F. Drug deposition of pressurized inhalation aerosols. Int J Pharm 1978; 1:205-12.

11 Wright BM, McKerrow CB. Maximum forced expiratory flow rate as a measure of ventilatory capacity. Br Med J 1959; 2:1041-7.

12 Snedecor GW, Cochrane WG. Statistical methods. Seventh edition. Ames, Iowa: State University Press, 1971.

13 Lippman M, Albert RE. The effect of particle size on the regional deposition of inhaled aerosols in the human respiratory tract. Am Ind Hyg Assoc J 1969; 30:257-75.

14 Morén F, Wetterlin K. Swedish Patent Application No 7612448-6. 1976.

15 Hume KM, Gandevia B. Forced expiratory volume before and after isoprenaline. Thorax 1957; 12:276-9.

16 Pain MCF, Read J. Patterns of response to bronchodilators in young patients with asthma. A ustralas Ann Med 1963; 12:216-20. 